\title{
Our Natural Systems: The Basis of all Human Enterprise
}

\author{
Margaret E. Robertson
}

\begin{abstract}
Making lifestyle adjustments to benefit the Anthropocene are fundamental for human survival. Whilst the powers of twenty-first century communications systems are celebrated there is a cautionary story needed to set the scene for global advancement. Humans are the custodians of planet earth and dependent on its resources for survival. Networking and communication advances assist the monitoring processes for making possible the survival of the planet and its flora and fauna.
\end{abstract}

Keywords Nature $\cdot$ Urban living $\cdot$ Memory $\cdot$ Community $\cdot$ Values

\section{Natural Systems as Foundational to Global Understanding}

Knowing how planet earth functions is fundamental for all human existence. Natural systems fulfil our basic needs for survival. Whilst this statement may appear self-evident the realization that current generations are growing up in residential spaces increasingly removed from their survival sources is cause for concern. On current estimates more than 60 percent of the world's people live in cities. Their likely experience of everyday life is being surrounded by buildings, transport links and service providers concentrated in local neighbourhoods - themselves constructions of urban living. City life transforms rural landscapes into high rise buildings, rapid transit systems, shopping and entertainment centres, paved surfaces, and ever depleting green spaces. Intricate transport and communication systems enable exchanges of supplies, products and knowledge. 'Community' and belonging are constructions of place which urban residents find or locate in their daily interactions with each other and the systems created.

One outcome for humankind's relationship with natural systems is spatial distancing from the source of supply. Urban access to water provides a simple illustration.

M.E. Robertson $(\bowtie)$

La Trobe University, Melbourne, VIC, Australia

e-mail: m.robertson@latrobe.edu.au 
Tap and bottled water, for instance, are critical for urban survival. However, their delivery to urban populations via collection points such as dams and reservoirs must flow through often complex network systems, including political borders in addition to purification and recycling plants, and various distribution systems. All of these flows are dependent on communication systems for transfer connections to their final destination points. Put simply, the biosphere landscape is being reengineered to suit our urban demands. Of course history shows that wherever human settlement has taken a grip on the landscape water diversion techniques are evident-for human consumption as well as for stock and crops. Viaducts, simple irrigation systems and water channels are the lifeline of many rural and village communities in more remote locations in present times. They remain as remnants of a lifestyle balance with nature that is largely gone. Today the scale of reordering of nature to meet urban demands, has, and is, reshaping our heritage. Illustrative are the hydro-electric dam projects, such as the Three Gorges Dam across the Yangtze River. The question for all humankind is at what cost for the planet?

For the purposes of this discussion three interacting forces are acknowledged. Each is impacting on the fragility of planet earth, and can, in part, be explained by information systems, flows and networks. Knowledge-based, and reliant on human usage the interoperability of these global systems has irrevocability changed the order of daily living. Predictability and certainty that were once hallmarks of a settled society are now fluid constructs which require community responsibility. Readiness to change is fundamental for learning how to live sustainably in our networked world. In brief the forces are:

- First, the natural ecological balance has been disturbed with resultant climate and atmospheric events, natural disasters including floods, fires, coastal erosion, defoliation and desertification. Making adjustments to benefit the Anthropocene can be considered fundamental for human survival.

- Second, the concentration of people into megacities exacerbates the disturbance of natural systems and adds to air, water and soil pollution.

- Third, the built landscape alters the imaginaries of people. Cities are reality. Farming life and food production are increasingly large scale commercial enterprises. The links between people, the land and the landscapes created, reflect affluent hegemonies where daily life has departed from rural subsistence forever. Decision making lenses need to be reminded of our dependence on, and fragile links, with nature.

\section{What We Know About Planet Earth and How Technology Is Helping}

Scientists argue about the status of the Anthropocene in geological time (Gibbard and Walker 2013; Rull 2013). The Holocene period marked the beginning of human activity on earth including agricultural development, towns and cities, and 
migration across continents. Paleontologists study plant and animal remains to determine historic changes in atmospheric conditions. Recent history during the latter part of the twentieth century appears to have entered a period of more marked change (Pawson 2015). This phase we define as the Anthropocene. Ecosystems are being pushed to accommodate massive growth in population, social systems and global networks that penetrate business and commerce; consumption including housing, energy and transport infrastructure; lifestyle choices including education, mobility and family, as well as decisions within macro global and local communities. In just a short period the changes in the earth's systems are remarkable. Some are listed below.

- Climate Change: "Human influence on the climate system is clear, and recent anthropogenic emissions of green-house gases are the highest in history. Recent climate changes have had widespread impacts on human and natural systems."1

- Greenhouse gases: The rise of greenhouse gas emission is contributing to increased incidences of drought, fires and tree mortality (Allen et al. 1999; Nurdiana and Risdiyanto 2015; Ren et al. 2015).

- Earthquake activity: Seismic activity monitored by increasingly sophisticated technology is able to forecast changes recorded at local stations. Active Earth Seismology contributes to human understanding of earth tectonics and hazardous locations ${ }^{2}$.

- Population increase: "In 1900, world population was 1.6 billion, a total that had taken at least 50,000 years of human history to accumulate. But by the year 2000, world population reached 6.1 billion, in large part because of a dramatic positive achievement: the rapid spread of modern medicine and public health practices after World War II, starting in the 1950s." (World Population Reference Bureau ${ }^{3}$ )

- Migration and the megacities: The post World War Two Human Rights Declaration has contributed to the movement of people in search of better social, economic and political circumstances. Added to this agreement has been the commodification of transport-particularly air travel. The poverty imbalance appears unaltered with African nations and parts of Asia being amongst the global poorest.

Since life on earth the biosphere and atmosphere have interacted to produce changes. In the past simple measures enabled changes to be recorded. For instance,

\footnotetext{
${ }^{1}$ See Intergovernmental Panel on Climate Change for full report at http://www.ipcc.ch/.

${ }^{2}$ See Active Earth interactive modelling at http://www.iris.edu/hq/programs/education_and_ outreach/museum_displays/active_earth/. See also the World Meteorological Organisation at https://www.wmo.int/pages/index_en.html.

${ }^{3}$ World Population Reference Bureau. See http://www.prb.org/Publications/Articles/2011/worldpopulation-7billion.aspx.
} 
Fig. 1 Stevenson's box

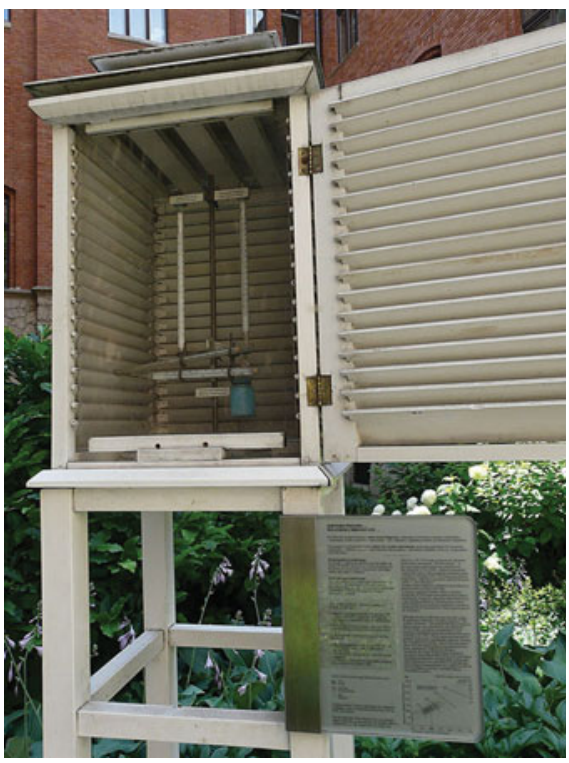

climate records relied on manual plotting of temperature, rainfall and pressure data collected from mostly volunteer recorders who used telephone, telegraphic signals and ground transportation to the nearest telephone device. Scattered around the globe the Stevenson's box (see Fig. 1) symbolizes the links between land, communications and human activity. Automated readings from ground fixtures are the major change of recent times. Nowadays global networks share information disseminating from weather stations into websites around the world without interruption.

Technology improvements enable sharing of data globally in real time via satellite networks and wireless enabled portals. Streaming live via Apps to mobile devices anywhere with satellite access can be viewed as distancing the user from the data source and underlying science. Given the end-user experience of smart technologies and personal mobile devices the lived experiences of an ever increasing urban based population could not be more different from those of their ancestral past of less than one hundred years ago. Is the new reality of information readily available 'in the hand' or at the tap of a portable screen good for our earth's future? At one level the answer must be yes. Being informed helps everyone make sound decisions about personal behaviours locally. The converse of this argument is that not knowing about the origins of the data contributes to unreal expectations about planet earth. 


\section{Mega Cities and the Millennial Lifestyle}

Until the mid-1800s there was relative harmony between humans and planetary systems. The human footprint was manageable. However, the development of machines for manufacturing, cars, trains and aeroplanes, electricity and radio communications marked the start of massive change. In the space of 3-4 generations humans have changed from being motivated by daily survival to consumer addicts. At the heart of much of their behavior is communication networks with incessant temptations to spend, spend and spend more on their personal wellbeing. Capital concentration in cities and the unstoppable modernization of major population nations including China and India is draining finite resources at rates that alarm the earth's scientists. Computer modelling of consumer lifestyles helps inform governments and policy makers of trends that are unsustainable (Peterson and Robertson 2012). Reversing human behavior or finding more sustainable ways to live the millennial lifestyle are major challenges. Data records reveal the stress on resources ranging across our basic needs - water, food and shelter. These are before considering demands for energy to drive electronic devices and development infrastructure including transport, machinery, and basic services including health and education.

Understanding the fragility of these sources of life on earth is a major task for education. Aimed at human survival into the future of the Anthropocene researchers strive to develop efficiencies in production processes that can reduce demand for finite resources. For instance:

- Water footprint: Recycling water in cities and reducing water intake in production processes are remediation strategies. Communicating water limits and education for household efficiencies can help change consumer habits.

- Green energy usage: Government's building policy codes reflect national commitment to the global challenges of climate change and limits on finite resources. Communicating practices through codes, labelling and monitored checks are constructive practices. Government initiatives in many nations include: upgrading electricity to low energy sources, solar paneling, and insulation in buildings, converting utilities to green energy sources, and finding alternatives such as methane gas for low energy usage.

- Public transport infrastructure: Private car ownership is one of the symbols of personal wealth that follows trends in rising GDP. Demand rises thus offsetting clean energy efficiencies. According to the OECD Library: "Since 1990, countries' efforts in introducing cleaner vehicles have been offset by growth in vehicle numbers and the increased scale of their use. This resulted in additional fuel consumption, $\mathrm{CO}_{2}$ emissions and road building. Road traffic, both freight and passenger, is expected to increase further in a number of OECD countries."4

\footnotetext{
${ }^{4}$ See OECD Library at http://www.oecd-ilibrary.org/sites/9789264185715-en/02/03/index.html? itemId=/content/chapter/9789264185715-20-en\&mimeType=text/html.
} 
- Renewable energy sources: Energy security is a major issue for modern nations. Challenges include competition for limited resources as well as expanding domestic needs. Non-renewable fossil fuels including coal and gas have increasing demand. However, as nations face complex issues surrounding their emissions and consider the merits of nuclear power sources as a viable alternative, renewables such as wind and solar power are adding substantially to existing renewable systems, including hydroelectricity. The energy grids are enhanced by political, economic and social awareness of the need for ethical and sustainable energy generation. Public awareness of the issues helps drive wise domestic decisions that create hope for the future.

\title{
Constructing Better Futures
}

Global indicators of increasing levels of consumption associated with rising wealth and associated lifestyle expectations mark the reality of the millennial condition. In his May 2015 Encyclical Pope Francis took the significant step of calling on the global community to change their habits:

\begin{abstract}
We all know that it is not possible to sustain the present level of consumption in developed countries and wealthier sectors of society, where the habit of wasting and discarding has reached unprecedented levels. The exploitation of the planet has already exceeded acceptable limits and we still have not solved the problem of poverty. The mindsets of individual consumers are the 'problem,.
\end{abstract}

People who currently consume in excess can also provide the solution and fast communication networks can hurry up the process of re-education. Consider, the population 'bomb' scenario described by Paul Ehrlich in the later 1960s could be linked with China's decision to implement its one child per family policy. Communicating and implementing this decision in the large country of China has contributed to the easing of the population bomb potential. In other parts of the world where poverty, high infant mortality rates and low life expectancy rates continue agencies such as the World Health Organization are assisting with family planning and disease eradication programs. Today the impact of population behaviours and associated consumption of global resources can be modelled using informatics tools such as geospatial technologies, mathematical modelling, hydro-modelling, archeological computing, as well as the increasing array of social media communication tools. Whatever the challenges ahead during the Anthropocene period the natural systems and their protection must take precedence. Our survival depends on radical behavior changes such as that which flowed from the Ehrlich (1968) wake-up call regarding population growth.

\footnotetext{
${ }^{5}$ See 'On care for our common home' at http://w2.vatican.va/content/francesco/en/encyclicals/ documents/papa-francesco_20150524_enciclica-laudato-si.html.
} 
Half a century later sharing of information is rapid and simple [see Moss et al. (2010) on climate change research]. Ranging from big data to personal communications the advent of satellite communications, underwater cabling and vastly improved service connectivity to the home, plus personal digital devices with tracking agencies, all translates to maximum impact. Disaster management relies on communications to affected locations via social media. The alarm systems of old are relatively inferior in comparison with the message speed via mobile connectivity. Added to this service, information flows related to food and water security as well as health services and agency support are improving the quality of community services globally. Examples of the links between improved communications and management of the planet's natural systems demonstrate effective ways in which humans can minimize their footprint.

\section{Example 1: Urban Agroecology}

In a nation where urbanization is a major feature of recent decades, China has been able to regulate and plan for ecological change. Publications within the Chinese scientific academy report on the innovative practices and smart usage of geo-spatial technologies that are reshaping city landscapes. As opportunities for developing new green resources become possible community action can help maintain and expand their usage. In older cities such as Beijing the issues are more problematic (see Chi et al. 2015) and like mega-cities in other global locations layers of the past along with the rapidity of immigration contribute to the urgency for solutions.

Helping to solve the problem, in part, a new green revolution in food producing areas is underway. Enhancing production and yields, Japan, for instance, offers leadership in the new era of sharing knowledge through easily established communication networks. Business economics working in conjunction with agro-science as well as biosecurity measures are revolutionizing production and product distribution.

\section{Example 2: Green Cities; Community Gardens}

Along with creative applications of informatics in urban design are innovative strategies for 'making' green spaces. Whist the allotment or small private and community gardens are part of the history of European cities, roof top and vertical gardens are examples of add-on features to buildings in contemporary design. Apartment dwellers who take up gardening related activities are not only becoming more self-reliant but are part of the sustainable urban living solution which includes reducing urban pollutants into the atmosphere. 

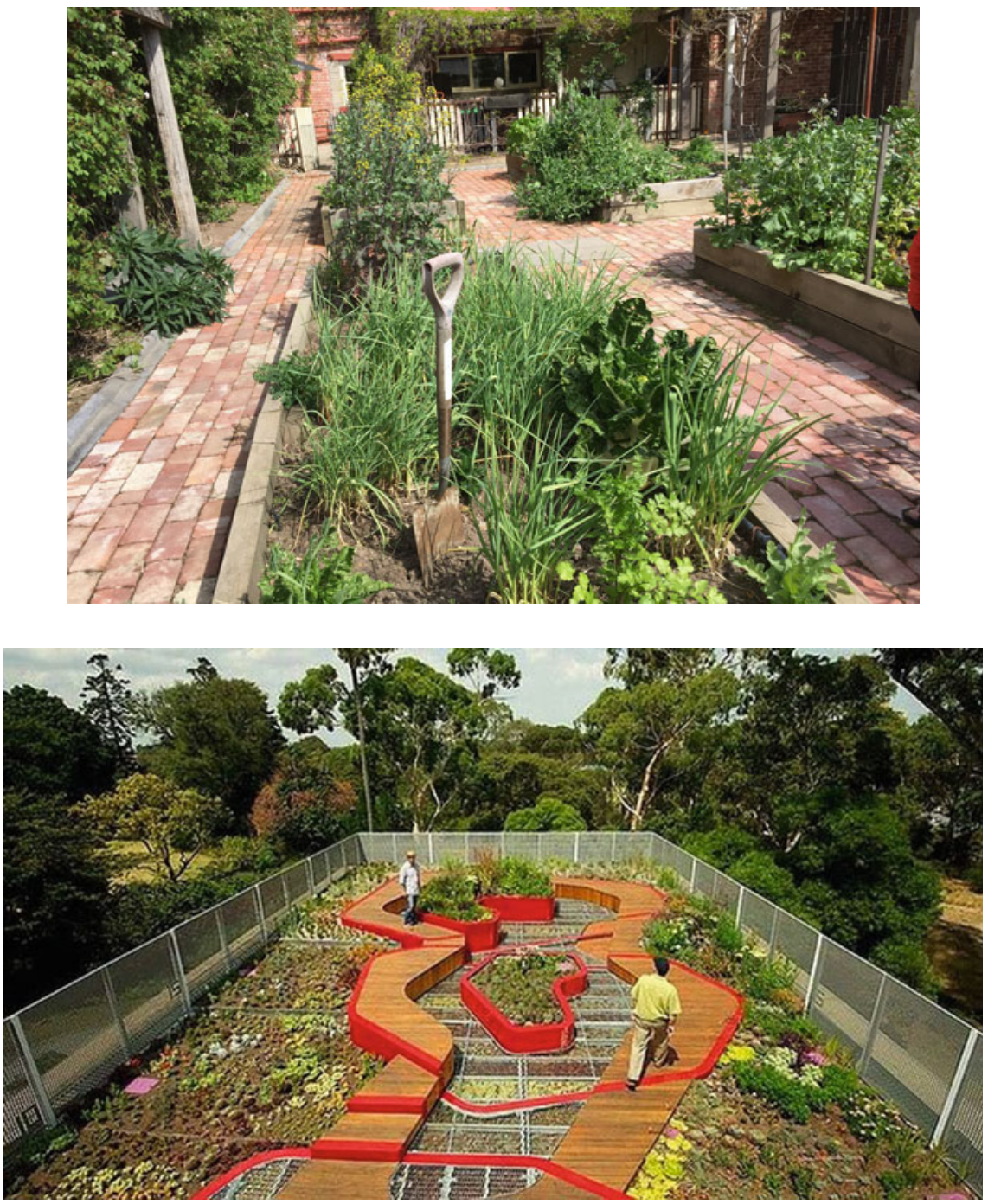

http://www.theage.com.au/victoria/extreme-gardening-on-the-92nd-floor-of-theeureka-tower-20150320-1m45sm.html.

\section{Example 3: Building Community}

As the process of urban growth and renewal systematically removes future generations from the rural landscapes of their ancestral pasts the matter of community and personal identity are becoming increasingly problematic. Cyclical rhythms of 
nature are a feature of community practices across cultures. Rituals are often associated with seasonal changes and moon cycles - these events in nature trigger rituals and myths that contribute to the collective memory of the people and their places. Communities evolve with, and from, these shared landscape memories with traditions and shared values expressed through language, art and architecture, habits and preferences. Collective activities may focus around the local park, schools, places of worship, shopping centres and recreation grounds or increasingly through online spaces. However, competing with this coming together for social interaction, more recent neo-liberal market forces of globalization are fueling the commodification of everyday living towards what Foucault (1970) describes as the governmentality of personal agency. The resultant fragmentation of local community building forces in the modern urban settlement can simply just happen with respect for nature being a causality. What we have is an urban ecology in transition from its close connection with nature to technology enabled and sustained built environments. Landscape designers, along with residents and citizens need to imagine new communities, and the affordances of online communications simplify common interest contact. Thirdspace (Oldenburg 1991; Soja 1996) and community networks (Newing 2010) may not have the materiality of past communities. However, they can help maintain the values and virtues associated with living a life well-in harmony with nature, and with respect for fellow beings.

\section{Our Planet}

Life on planet earth demands a balance between the natural systems, and human achievements. Digital technologies are perhaps the greatest wonder of our Anthropocene age. They can both model and enable better futures for humanity through relief of poverty and abuse, and/or act as a negative force as the architect of the planet's destruction. Understanding the fragility of planet earth and assisting morally defensible decision making is thus a product of networking and communications.

Open Access This chapter is distributed under the terms of the Creative Commons Attribution 4.0 International License (http://creativecommons.org/licenses/by/4.0/), which permits use, duplication, adaptation, distribution and reproduction in any medium or format, as long as you give appropriate credit to the original author(s) and the source, provide a link to the Creative Commons license and indicate if changes were made.

The images or other third party material in this chapter are included in the work's Creative Commons license, unless indicated otherwise in the credit line; if such material is not included in the work's Creative Commons license and the respective action is not permitted by statutory regulation, users will need to obtain permission from the license holder to duplicate, adapt or reproduce the material. 


\section{References}

Allen, J., Mssey, D., and Pryke, M. 1999. Eds. Unsettling cities: movement/settlement. London: The Open University.

Chi, W., Shi, W. and Kuang, W. 2015. Spatio-temporal characteristics of intra-urban land use change in Beijing, China between 1978 and 2010. Journal of Geographical Sciences, 25(1), 3-18.

Ehrlich, P. 1968. The Population Bomb. Rivercity Mass.: Rivercity Press.

Foucault, M. 1970. (trans). The order of things. An archaeology of the human sciences. New York: Random House..

Gibbard, P.L. and Walker, M.J.C. 2013. The term 'Anthropocene' in the context of formal geological classification. Geological Society of London, Special Publications: doi 10.1144/ SP395.1

Moss, R., Edmonds, J., Hibbard, K., Manning’ M., Rose, S., van Vuuren, D., Carter' T., Emori, S., Kainuma, M., Kram' T., Meehl' G., Mitchell, J., Nakicenovic,' N., Riahi,' K., Smith, S., Stouffer,' R., Thomson, A., Weyant,' J. and Wilbanks, T. 2010. The next generation of scenarios for climate change research and assessment. Nature, 463, 747-756.

Newing, H. 2010. Bridging the gap: Interdisciplinarity, biocultural diversity and conservation. In Nature and culture. Rebuilding lost connections, eds. S. Pilgrim and J. Pilgrim, 23-40. London: Earthscan.

Nurdiana, A. and Risdiyanto, I. 2015. Indicator determination of forest and land fires vulnerability using Landsat-5 TM data (case study: Jambi Provence). Procedia Environmental Sciences 24, 141-151.

Oldenburg, R. 1991. The Great Good Place. New York: Marlowe \& Company.

Pawson, E. (2015) What sort of geographical education for the Anthropocene? Geographical Research, 53(3), 306-312.

Peterson, J., and Robertson, M. 2012. Spatial models as a hub for sustainability education: Exemplifying the transition from producer to user-defined maps in the classroom: In Schooling and learning for sustainable development An Asia-Pacific regional focus, ed. M. Robertson, 199-214. Dordrecht: Springer.

Ren, Z., Zheng, H., He, X., Zhang, D.,Yu, X., and, Shen, G. 2015. Spatial estimation of urban forest structures with Landsat TM data and field measurements. Urban Forestry and Urban Greening, 14, 336-344.

Rull, V. 2013. A futurist perspective on the Anthropocene. The Holocene, 23(8) 1198-1201.

Soja, E. W. 1996. Thirdspace. Malden (Mass.): Blackwell. 